\title{
Research into electric power communications network overhaul management system
}

\author{
Zhirong Liang ${ }^{1, a}$, Dawang Cheng ${ }^{1, b}$ \\ ${ }^{1}$ Chinese people's Liberation Army Armored Forces Academy, Anhui, 233000, China \\ a476772954@qq.com, b595932678@qq.com
}

Keywords: Electric power telecommunication; Communication

Abstract. To adopt electric power communications network overhaul management system for
electric power communications network management can increase the regularity of communication
overhaul and the operation reliability of communication network. Based on that, this paper studies the
electric power communications overhaul management system from the perspective of system' s
application demands and operation so as to provide helpful references for those interested in the field.

\section{Introduction}

In recent years, the development of the electric power communications network has entered the full-scale construction stage, leading to intelligentization of the electric power communications network management. The electric power communications network overhaul can enhance the security risk management of the communications network, and promote intelligentization and informatization of electric power communications construction. Therefore, it is imperative to study electric power communications network overhaul management system so as to make better use of the system to boost the electric power undertaking.

\section{Demand analysis of electric power communications network overhaul management}

During the operation and management process of the electric power communications network, communications overhaul management is of important significance. To conduct communications overhaul management according to the operation and management demands of the electric power communications network can increase standardization and scientification of electric power communications network operation and management. At the same time, corresponding overhaul plans can be formulated in view of the operation status of the electric power communications network equipment. These plans can prevent communications network equipment from going wrong, thus guaranteeing normal operation of electric power enterprises. Therefore, against the social backdrop of accelerating electric power communications network, it is necessary to conduct proper network communications overhaul management so as to better support the development of the electric power undertaking.

\section{Research into the electric power communications network overhaul management system}

\section{A. Analysis of the system structure}

In terms of the system structure, the electric power communications network overhaul management system should be made up of three parts, namely the database, the server and the communications management system. During the operation process, the system can rely on the communications network management system to obtain the status parameters of communications equipment and mark the communication status of the communications network. Analysis of the scores can help immediately reveal communications problems with the communications network and remove them to ensure the reliable operation of the communications network. Structurally speaking, the system's data input module can acquire all status parameters of the communications equipment, and conduct read-in of all these parameters into the server ${ }^{[1]}$. By checking the status rating table in the system 
database, the server can obtain the scores of every state parameter of the communications equipment and mark the equipment according to the corresponding marking standard. Finally, the system's client-end sends the scores and the overhaul reports to the system users to provide users with bases to conduct communications network overhaul management.

\section{B. Evaluation of the communications network status}

While evaluating the communication status, it is necessary to build the status parameter system for communications equipment. Based on the system, the status parameters of the communications network equipment can be classified and the corresponding equipment status parameter marking table can be formulated so as to provide data bases for the system's evaluation of the communications network status. When it comes to classification of status parameters, a layered structural model should be designed to finish parameter classification under the guidance of experts and based on past experiences and literatures. Currently speaking, the overhaul management system divide the electric power communications network environment into four kinds, namely fiber interface environment, electricity interface environment, power source environment and equipment environment. Every status contains several parameters. For example, the fiber interface parameters contain receiver power, error second counting, laser temperature, etc. Besides, changes of every parameter can influence the communication situation of the communications network to some extent. When it comes to the design of the system's marking standards, ten groups of parameters under the normal operation status of the equipment can be obtained, and the data average can be adopted as the standard for status parameters ${ }^{[2]}$. Comparison of the real-time communication situations of the communications network and the standard value can reflect the equipment's operation status. The smaller the deviation between the two is, the higher the scores of the communication status are.

\section{Communications status overhaul}

In terms of the overhaul of the communications network, relevant personnel can consult experts or investigate to acquire lots of parameter information about the communication status, and collect parameters from the electric power communications network. After the status parameter system is built, the matrix to judge the status parameters can be built. Then, compatible matrix changes can be utilized to conduct matrix transformation to keep various parameters in consistency. After that, the weight of various status parameters is calculated. Based on that, the scores of communications equipment can be acquired. According to the current reliable evaluation model of the electricity communications network, the structure of the matrix, $A=\left(a_{i j}\right)$, can be judged according to Eq. (1) below:

$$
\left\{\begin{array}{l}
a_{i i}=1 \quad(i=1,2, \cdots, n) \\
a_{i j}=1 / a_{j i}(i, j=1,2, \cdots, n) \\
a_{i j}>0 \quad(i, j=1,2, \cdots, n)
\end{array}\right.
$$

Where, $a_{i j}$ is the ratio of $X_{i}$ to $X_{j}$, standing for the ratio of the degree of importance of the lower-layer indexes to that of the upper-layer indexes. These data can be acquired from the on-site experiment and the expert consultation, and can be marked by the scale method from 1 9 ${ }^{[3]}$. Based on the compatible matrix, Eq. (2) below can be adopted to judge matrix transformation and turn it into the compatible matrix, $B=\left(b_{i j}\right)$, in line with the consistency condition of $b_{i j}=b_{i k} * b_{k j}$.

$$
\mathrm{b}_{i j}=\sqrt[n]{\prod_{k=1}^{n} a_{i k} * a_{k j}}
$$

During weight calculation, Eq. (3) below can be used to calculate the weight of various parameters. Then, the numerical processing software can be adopted to finish processing of various parameters so as to reduce the workload of weight calculation. When the communications network status is to be judged, Eq. (4) below can be adopted to work out scores of the communications network status. 


$$
\begin{gathered}
W_{\mathrm{j}}=\frac{\mathrm{c}_{j}}{\sum_{k=1}^{n} c_{k}}, \mathrm{c}_{j}=\sqrt[n]{\prod_{k=1}^{n} b_{j k}} \quad(j=1,2, \cdots, n) \\
S=\sum A_{j} \sum B_{i} C_{i}
\end{gathered}
$$

Where, $S$ stands for the scores of the communications network status; $A_{j}$ stands for the weight of equipment; $B_{i}$ stands for the status parameter weight; $C_{i}$ stands for the status parameter scores. At last, when the overhaul report is analyzed, if the communications network status scores are within 9.5 10 points, it suggests that the equipment of the communications network calls for no overhaul; if scores fall within 8.5 9.5 points, it suggests that the equipment of the communications network can work normally within a short time; if scores fall within $7 \sim 8.5$ points, it suggests that the equipment of the communications network calls for overhaul, and the overhaul can be arranged according to the practical conditions; if scores fall within $6 \sim 7$ points, it suggests that the equipment of the communications network is abnormal and calls for the arrangement of immediate overhaul; if scores fall below 6 points, it suggests that the equipment of the communications network should be immediately overhauled ${ }^{[4]}$.

\section{System realization}

To realize the electric power communications network overhaul management system, the resources management module, the status calculation module, the performance parameter management module and the client-end display module should be built. Among them, resources management module can store all the basic information within the system, and can provide convenience for the storage of the overhaul information; the performance parameters management module is responsible for recording the communication performance parameters of the communications network, and calls for a marking standard to decide parameters; the status calculation module should mark the communications equipment status according to the standards provided by the performance parameters management module. Therefore, lots of parameter data calculation is required, making it becoming the core of the system. The client-end display module can exhibit the overhaul report through the user interface so as to provide data for users' overhaul management of the communications network. Therefore, during the system realization, various modules should cooperate with each other well so as to rapidly and efficiently collect and analyze the communications equipment parameters of the electric power communications network and give reasonable overhaul suggestions.

\section{Summary}

All in all, during the electric communications network operation and management process, whether the communications equipment can steadily operate can directly influence the operation profits of electric power enterprises. The adopton of the electric power communications network overhaul management system for the communications network management can help immediately discover potential faults of the communications equipment to avoid the occurrence of faults of the communications network. Therefore, to study the electric power communications network overhaul management system can provide more guarantee for the electric power communications network overhaul practices.

\section{References}

[1] Liu X X, Lai C L, Du H B, et al. Applications of 3D GIS technique in electric power telecommunications resource management system [J]. Telecommunications for Electric Power System, 2012, 11: 1-16.

[2] Jia Z, Zhang Y \& Sheng L. Electric power communications maintenance management based on the TMS [J]. Information \& Communications, 2013, 10: 166. 
[3] Zhang L \& Ding W Q. Research and application on quantitative risk assessment for communication network maintenance [J]. Telecommunications for Electric Power System, 2013, 10: 166.

[4] Yu Q. Research and design of Taizhou' s electric power communications monitoring and management system [J]. Management \& Technology of SME, 2013, 04: 264. 